ARTIGOS

\title{
Monitoria como espaço de formação docente inicial em biologia sensível à diversidade cultural
}

\author{
Geilsa Costa Santos Baptista \\ Universidade Estadual de Feira de Santa (UEFS) \\ Feira de Santana, Bahia-BR \\ ORCID: https://orcid.org/0000-0002-5871-0115
}

Laryssa Carneiro Santos Universidade Estadual da Bahia (UEFS)

Feira de Santana, Bahia-BR

\begin{abstract}
RESUMO: Apresentamos e discutimos os resultados de um estudo qualitativo cujo objetivo foi analisar a contribuição da monitoria em um componente curricular do curso de Licenciatura em Ciências Biológicas da Universidade Estadual de Santana, para a formação da identidade docente de uma licencianda que seja sensível à diversidade cultural. Trata-se de uma autobiografia, com coleta de dados baseada em anotações em diário de campo e análise de conteúdo. Quatro categorias temáticas foram geradas, indicando que a monitoria contribuiu na sensibilização da licencianda sobre a necessidade de atenção e consideração da diversidade cultural presente na sala de aula, e do respeito dos diferentes conhecimentos e práticas presentes no universo escolar.
\end{abstract}

PALAVRAS-CHAVE: Monitoria;Identidade docente; Diversidade cultural; Empatia e afetividade.

\section{Monitoring as an initial teacher training space in biology sensitive to cultural diversity}

\begin{abstract}
We present and discuss the results of a qualitative study whose objective was to analyze the contribution of a monitoring, in a curricular component of the Degree in Biological Sciences in State University of Feira Santana, to the formation of the teaching identity of a student sensitive to cultural diversity. It is an autobiography, with data collection based on field annotations and Context Analysis. Four thematic categories were generated, indicating that the monitoring contributed to the awareness of the student about the need for attention and consideration of the cultural diversity present in the classroom, and the respect of the different knowledge and practices present in the school universe.
\end{abstract}

KEYWORDS: Monitoring; Teacher identity; Empathy and affection 


\section{autêntica}

DOI https://doi.org/10.31639/rbpfp.v\%vi\%i.284

\section{Monitoria como espacio de formación docente inicial en biología sensible a la diversidad cultural}

RESUMEN: Presentamos y discutimos los resultados de un estudio cualitativo cuyo objetivo fue analizar la contribución dela monitoria en un componente curricular del curso de Licenciatura en Ciencias Biológicas en la Universidad Estatal de Santana, para la formación de la identidad docente de un estudiante sensible a la diversidad cultural. Se trata de una autobiografía, con recopilación de datos basada en anotaciones de diario de campo y análisis de contenido. Se generaron cuatro categorías temáticas, lo que indica que la monitoria contribuyó a sensibilizar al alumno sobre la necesidad de atención y consideración de la diversidad cultural presente en el aula, y el respeto por los diferentes conocimientos y prácticas presentes en el universo escolar.

PALABRAS-CLAVE: Monitoria, Identidad docente; Empatía y afectividad 


\section{autêntica}

DOI https://doi.org/10.31639/rbpfp.v\%vi\%i.284

\section{INTRODUÇÃO}

A formação do professor é um processo prolongado e complexo, que envolve as suas experiências e transformações, podendo ter interferências do seu contexto histórico e cultural, mas, sobretudo, da reflexão sobre e na prática(BENITES,2012). Essa reflexão, por sua vez, submerge muitos desafios, entre eles as demandas que são inerentes à própria profissãoe a responsabilidade social de contribuir para que os sujeitos possam exercer a cidadania de maneira participativa ecrítica(LEITE et al., 2018).

A reflexão sobre e na prática pedagógica requer do professor oidentificar-se com a profissão, o que vai além do simples domínio de conteúdos específicos de cada área, envolvendo também desejos, emoções e problematização dos aspectos associados à didática para o desenvolvimento de competências e habilidades que lhe permitirão atuar com professor.

No caso da formação do professor de ciências, acreditamos ser necessário o desenvolvimento de competências e habilidades para o ensino que esteja ligado à interculturalidade, ou seja, ao diálogo entre a cultura científica e as culturas dos estudantes. Para Baptista (2014), a realização do diálogo intercultural nas aulas de ciências necessita investigar e compreender quais são os conhecimentos culturais dos estudantes e como eles podem se relacionar com os conhecimentos científicos, seja em termos de semelhanças e/ou de diferenças. O diálogo no ensino de ciências é uma relação de comunicação que é estabelecida entre o professor e os estudantes, e mesmo entre estudantes, a fim de exposições significações de conhecimentos que são culturais e que estão ligados a um tema que é objeto de ensino e aprendizagem.

De acordo com Baptista (2014), a formação dos professores de ciências pautada no desenvolvimento de competências e habilidades para a realização do diálogo intercultural contribui para que os professores possam tornar-se sensíveis à diversidade cultural. Neste sentido, o propósito deste artigo éapresentar e discutir os resultados de um estudo qualitativo cujo objetivo geral foi analisar quais as contribuições das vivências de uma licencianda em biologia - como monitora de um componente curricular da Licenciatura em Ciências Biológicas da Universidade Estadual de Feira de Santana (UEFS) que busca, entre outras metas, o desenvolvimento de competências e habilidades para o diálogo intercultural no ensino de ciências - para a formação da sua identidade docente inicial em biologia que seja sensível à diversidade cultural.

\section{MONITORIA E FORMAÇÃO DE PROFESSORES: BREVE ESTADO DO CONHECIMENTO}

Segundo Frison e Moraes (2010), a monitoria docente teve início na Inglaterra do final do século XVIII com Joseph Lancaster, com o método de ensino denominado Ensino Mútuo ou Monitorial, sendo posteriormente difundido em outros países da Europa e da América Latina. Ainda segundo estes autores, esse método surgiu com o propósito de suprir a falta de professores naquele país e no Brasil sua introdução se deu pela mesma razão, no ano de 1827, como alternativa para a falta de professores que foi decorrente da expulsão dos jesuítas.

Segundo Rátiva (2013), no método monitorial (Lancaster), o monitor era o aluno considerado o mais adiantado, que recebia orientações de um professor e depois repassava essas orientações aos demais alunos, sempre de forma oral e com vistas à repetição e memorização. Um professor chegava a atuar com trezentos alunos, ou mais, sempre supervisionando o monitor e os demais alunos.

É importante destacar que o método monitorial estava ligado às escolas normal, que recebeu esse nome do ministro francês Lakana, em 1794, para fazer referência a escola que dava a normas didáticas ao docente 


\section{autêntica}

DOI https://doi.org/10.31639/rbpfp.v\%vi\%i.284

(VALENCIA, 2006). No Brasil, a primeira escola normal foi criada em Niterói (RJ), em 1835, e tinha por finalidade preparar futuros docentes para dominar, na teoria e na prática, o método lancasteriano para ensinar a ler e escrever (RÁTIVA, 2013.

$\mathrm{Na}$ atualidade, o objetivo da monitoria não prioritariamente está atrelado a superar ausência de professores e nem divulgar o método monitorial, mas sim contribuir para melhorias nas práticas pedagógicas e formação docente (FRISON; MORAES, 2010). Neste sentido, a Lei de Diretrizes e Bases da Educação Brasileira (LDB número 9.394/1996), no seu Art.84, indica que "os discentes da educação superior poderão ser aproveitados em tarefas de ensino e pesquisa pelas respectivas instituições, exercendo funções de monitoria, de acordo com seu rendimento e seu plano de estudos". Disto, entende-se que a função dos professores nas universidades é mediar a formação dos futuros educadores, gerando espaços de experiências de ensino e pesquisa com vista às aprendizagens pautadas no trabalho colaborativo.

Hoje, a monitoria acadêmica vem constituindo trabalhos colaborativos, que contribuem tanto para a formação dos professores universitários quanto para a formação docente inicial (FRISON,2016), porque abre espaços para a realização de diálogos, questionamentos e reflexões por parte dos sujeitos envolvidos, o que, certamente, influencia na identidade docente. No trabalho colaborativo, de acordo com Carvalho (2017), ocorre construção de parcerias em prol do encontro de respostas para problemas que são colocados em pauta; da busca por superar a lacuna existente entre teoria e prática/ universidade e escola. O trabalho colaborativo envolve professores e futuros professores comprometidos em torno de uma problemática comum que pode envolver, também, a construção de conhecimentos coletivos ligados à prática pedagógica e desenvolvimento profissional docente.

\section{METODOLOGIA}

\section{Abordagem da pesquisa}

Esse trabalho, de natureza qualitativa (BORTONI-RICARDO, 2008), está amparado em narrativa autobiográfica a qual, segundo Souza (2006), é um relato oral ou escrito, recolhido através de entrevista ou de diários pessoais e tem por objetivo a coleta de dados para compreensão das vivências dos sujeitos em diferentes contextos das suas vidas. Ainda segundo Souza (2006), a narrativa autobiográfica é muito importante para o contexto da formação de professores (inicial ou continuada), pois permite retratar, na fala da própria pessoa, como ocorre seus vínculos com o mundo.Isto implica na externalização do futuro professor e do professor em exercício das suas relações com os pares que acontecem nas instituições de ensino superior e nas escolas, e demais segmentos sociais. Consequentemente, abre espaço para investigações e reflexões que contribuam para melhorias nas práticas pedagógicas.

\section{Contexto e sujeito da pesquisa}

A pesquisa foi desenvolvida em 2018, no segundo semestre letivo, no espaço físico da UEFS. Particularmente na sala de aula do componente curricular Pluralidade Cultural e Inclusão Escolar (Código EDU 354 - Departamento de Educação da UEFS), que é ofertado no terceiro semestre do curso de Licenciatura em Ciências Biológicas (Departamento de Ciências Biológicas, UEFS) e possui carga horária total de 75 horas, sendo 5 horas por semana.

Segundo sua ementa, EDU 354 pretende conduzir os licenciandos à: - compreensão da escola como espaço sociocultural; - Refletir sobre a diversidade dos sujeitos, a produção do conhecimento biológico e as 


\section{autêntica}

DOI https://doi.org/10.31639/rbpfp.v\%vi\%i.284

questões das diferenças de gênero, de corpo, de sexualidade; - A relação entre ciência e outras formas de conhecimento no âmbito da educação; - Cruzamento de fronteiras culturais na aprendizagem de Ciências e Biologia em diferentes contextos educativos.

O sujeito da pesquisa foi uma estudante da Licenciatura em Ciências Biológicas da UEFS (ingresso no segundo semestre de 2014), primeira autora deste artigo,que atuou como monitora do referido componente no semestre em que foi desenvolvida a pesquisa. Possui experiência de ensino nas escolas da rede pública de ensino (municipal e estadual) na cidade de Feira de Santana, Bahia, com contratação na modalidade de professora temporária desde o ano de 2015, nas disciplinas ciências naturais e biologia.

A professora orientadora é graduada em Licenciatura em Ciências Biológicas pela UEFS, tem mestrado e doutorado em Ensino, Filosofia e História das Ciências pela Universidade Federal da Bahia (UFBA); experiências de ensino na escola básica e universidade há 21 anos. Na escola da rede pública e particular de ensino da cidade de Feira de Santana, Bahia, como professora de ciências e biologia entre os anos de 1998 e 2007. Na universidade, como professora titular na graduação e pós-graduação e pesquisa junto ao Departamento de Educação da UEFS, tendo ingressado como professora auxiliar no ano de 2002.

Segundo informações obtidas junto à Pró-Reitoria de Graduação da UEFS em 17.07.2019, no endereço eletrônico:http://www.prograd.uefs.br/modules/conteudo/conteudo.php?conteudo=23), a monitoria é a denominação dada ao processo de iniciação à docência, oportunizado aos alunos dos cursos de graduação, no intuito de contribuir para a formação acadêmico-profissional numa determinada área do conhecimento e tem duração de 12 (doze) meses ininterruptos. Os objetivos da monitoria são: proporcionar ao estudante de graduação, a oportunidade de engajar-se em plano de trabalho de atividades de ensino que possibilitem o aperfeiçoamento do conhecimento e o desenvolvimento de atitudes e habilidades favoráveis à sua formação acadêmica e profissional; Criar condições de aprofundamento teórico e desenvolvimento de habilidades relacionadas à atividade docente;Estabelecer práticas e experiências pedagógicas que permitam a interação dos estudantes monitores com o corpo docente, discente e técnico administrativo.

A monitora participante da presente pesquisa foi aprovada através do edital UEFS número 001/2018. Suas atividades foram distribuídas em 12 horas semanais dentro do plano de trabalho elaborado pela professora orientadora, "Formação inicial para a prática pedagógica em biologia sensível à diversidade cultural",o qual teve por objetivo contribuir para ampliar as oportunidades de interações e aprendizagens da docência para o diálogo intercultural no ensino de biologia da escola básica.

As atividades pontuadas para a monitoria foram: - Participação nas reuniões do Grupo de Investigações em Etnobiologia e Ensino deCiências (GIEEC-UEFS),com o propósito de interagir e refletir sobre as pesquisas voltadas para o ensino de ciências e diálogo intercultural; - Realizar consultas aos periódicos da área de ensino de ciências de forma a ampliar o seu universo teórico e conceitual. - Participar das atividades em sala deaula no componente curricular Pluralidade Cultural e Inclusão Escolar; - Identificar e discutir momentos para que vivencie experiências pedagógicas nas salas de aula da UEFS e nas escolas; - Participar das atividades de planejamento com a professora orientadora; - Auxiliar a orientadora na realização de trabalhos práticos, na preparação de recursos e sequências didática, em atividades de classe na UEFS, nas escolas e a partir das saídas de campo; - Dar assistência aos estudantes na resolução de exercícios e esclarecimento de dúvidas; - Auxiliar na elaboração de recursos didáticos complementares às aulas. 


\section{autêntica}

DOI https://doi.org/10.31639/rbpfp.v\%vi\%i.284

\section{Coleta e análise de dados}

Para coleta de dados utilizamos a autobiografia a partir de anotações pela monitora num diário de campo acerca das suas percepções e questionamentos durante todas as atividades pontuadas para a monitoria (ver atividades no item acima).O propósito foi analisar os registros da e com a própria monitora sobre as suas vivências para que fosse possível refletir sobre ela de maneira colaborativa, entre monitora e professora orientadora.

A análise sobre as anotações no diário de campo procedeu-se mediante a Análise de Conteúdo de Bardin (2006), quando foram selecionados, organizados e interpretados indutivamente e em diálogo com a literatura específica da área de ensino de ciências. Assim, o presente trabalho apresenta as inferências e significações da monitora conjuntamente com sua orientadora.

\section{RESULTADOS E DISCUSSÃO}

A leitura e análise do diário de campo nos permitiu a geração de quatro categorias temáticas. A seguir, essas categorias serão apresentadas e nelas as narrativas da licencianda seguidas de discussão.

\section{Categoria 1:Planejamento de ensino: questionamentos e necessidade de reformulações.}

As interações da monitora com a professora orientadora e com os demais licenciandos em biologia que frequentavam EDU 354 no semestre 2018.2 Ihe permitiu atenção especial para a necessidade de replanejamento das atividades de ensino, um tópico de bastante relevância na prática pedagógica e formação do professor.

Quando a licencianda iniciou a monitoria, a professora orientadora já havia planejado as aulas do semestre em curso, porém, no decorrer dos encontros, surgiu a necessidade de adequações que melhor atendessem as necessidades da turma. Porque os licenciandos se apresentavam desmotivados, sendo preciso sair de aulas expositivas, ainda que estivessem acontecendo de maneira dialógica, para inovações com dinâmicas de grupos.Na transcrição que segue, podemos constatar essa percepção da monitora:

Logo no início percebi o quanto é importante revermos sempre os planejamentos de ensino. Esse tema é muito importante para a formação do professor, mas não é tão discutido durante a licenciatura em biologia. Esta semana percebemos a importância de mudar as aulas para motivar mais a turma que disse perceber as aulas como cansativas pela carga horária alta nos dias de sextas-feiras. Propomos um Quiz com 10 questões em que trazíamos a história do nosso país e as relações étnico raciais. Falamos sobre quantas pessoas foram e ainda são mortas por terem em seus fenótipos uma cor que não era e é aceita pela sociedade e da importância de nós professores falarmos sobre esse assunto nas salas de aula durante todo tempo, e não somente no dia da consciência negra. Em conversas informais com os alunos eu percebi o quanto muitos passam por preconceitos e dificuldades neste sentido. A educação precisa tomar consciência do seu papel, pois somos transformadores, acesso de mudança de pensamento por uma massa que sobrevive aos processos de marginalização. A dinâmica do Quizauxiliou na motivação da participação para fomentar nossa discussão sobre as relações étnico raciais.

É interessante notar a percepção da monitora sobre o planejamento das aulas, especialmente porque entendemos que o professor precisa ser flexível ao refazer os seus planos, caso contrário correrá o risco de não alcançar os objetivos educacionais pontuados. Como bem argumenta Veiga (2008), o planejamento da prática 


\section{autêntica}

DOI https://doi.org/10.31639/rbpfp.v\%vi\%i.284

pedagógica é uma tarefa docente que inclui as ações de ensino para o alcance dos objetivos propostos, podendo ser flexível e refeito, a depender da necessidade de adequação às diferentes turmas e suas realidades.

A monitora também percebeu o quão necessário é o envolvimento dos estudantes na escolha das formas como serão avaliados, como é possível observar na sua narrativa abaixo:

Nas minhas conversas informais com os alunos, eles contribuíram na escolha das opções propostas de avaliação. E então foi escolhida a produção de um recurso didático, o que acho que foi muito produtivo para incentivar os alunos a produzirem aulas criativas quando estiverem em sala de aula no futuro.

De fato, a literatura da área de ensino de ciência comprova essa necessidade de envolvimento dos estudantes nos processos avaliativos. Para Dantas et al. (2017), a avaliação é uma componente chave na dinâmica do funcionamento didático e educacional, mas ela não pode ser praticada tendo em conta apenas o professor,o sistema de notas e classificação. É preciso considerar que "[...]a avaliação permeia todas as perspectivas de busca de novas metodologias e alternativas ao processo de melhoria do ensino e aprendizagem" (DANTAS et al., 2017, p. 28) e entendemos que isto inclui a participação ativa dos professores e dos estudantes, quando juntos poderão "[...]oferecer elementos importantes a respeito das dificuldades práticas de avaliar em uma sala de aula heterogênea" (DANTAS et al., 2017, p. 28).A sala de aula é composta por diferentes culturas que se fazem presentes através dos estudantes e professores e, portanto, por diferentes visões de natureza. Essas visões não podem ser desprezadas, mas sim aproveitadas como base para interações e significações, que poderão ser explicitadas nos momentos das avaliações, incluindo as somativas, que valem notas.

\section{Categoria 2: A importância e o papel da afetividade no processo de aprendizagem}

As interações da monitora com a turma de EDU 354 também geraram reflexões acerca da importância de que as tentativas de relações de comunicação dialógica aconteçam não apenas entre o professor e os estudantes, mas, também, entre os estudantes:

Percebo que a turma é composta, na maioria, por licenciandos que ingressaram juntos no curso, sendo eles do mesmo semestre, porém, tem licenciandos de outras turmas. Eu percebo que eles ficam intimidados, envergonhados diante dos colegas por não serem conhecidos. Isto dificulta as suas participações para que comuniquem as suas ideias. Acho importante tentar motivá-los a conversarem entre si, pois isso pode gerar mais afetividade e atenção uns com os outros, e quem sabe melhorar as suas participações nas aulas.

Entendemos que o diálogo nas salas de aula é promovido quando ocorre motivação das falas entre os sujeitos, mas o falar requer a afetividade, enquanto desejo de relação do eu com o outro, tornando possível a construção de conhecimentos e desenvolvimento pessoal. No caso da formação do futuro professor, é essencial o envolvimento do docente universitário, considerando a afetividade como parte do desenvolvimento profissional, que busca despertar a atenção de uns para com os outros(VERAS; FERREIRA, 2010).

A monitora conjuntamente com a professora orientadora buscou, durante todas as atividades, gerar espaço para a afetividade entre os licenciandos, especialmente com palavras de motivações para interações como, por exemplos: "Conversem entre si";"escutem as opiniões dos colegas"; "O que vocês acham?"; "Vocês gostariam de explicar o que pensam sobre este assunto?". Isto abriu espaço para demonstração dos 


\section{autêntica}

DOI https://doi.org/10.31639/rbpfp.v\%vi\%i.284

sentimentos e emoções entre os sujeitos e destes com os conteúdos que estavam sendo estudados. Esta afirmativa decorre da seguinte transcrição das anotações da monitora no seu diário:

Percebo que minha participação como monitora está sendo essencial para motivar ainda mais o diálogo, com a participação de todos. Vejo que a monitora está sendo essencial por contribuir que os colegas se sintam mais à vontade, por ter na sala ajudando a professora uma licencianda com eles. Acho que isso está dando mais espaço, quebrando mais o distanciamento entre nós. É interessante observar como como isso ajudana solução de questionamentos e problemas que surgem durante as aulas, além de facilitação da aprendizagem.

\section{Categoria 3:A teoria como suporte ao melhor entendimento da prática pedagógica relacionada com diversidade cultural}

A docência, de acordo com Pimenta e Lima (2006), é uma dinâmica entre a teoria e a prática. Na transcrição a seguir, percebemos que a monitora reconhece a importância dessa relação, o que é um aspecto muito importante para a formação de qualquer professor, em qualquer nível de ensino e área.

Leituras sobre a ementa de EDU 354, e o acompanhamento das aulas, me proporcionou a percepção de que esse componente permeia as várias faces da cultura e os aspectos que envolvem as discussões em sala de aula, sobre preconceitos, discriminações, intolerâncias, por exemplo a religiosa, a diversidade de gênero, entre outros. A partir das discussões dos textos acerca das teorias que falam do ensino de ciências e essas questões vejo que ocorre uma troca de informações entre a professora e os alunos sobre essas dificuldades, com exemplos de situações cotidianas que acontecem nas escolas. Situações muitas vezes percebidas por eles (licenciandos em biologia) dentro das escolas, que serão seus espaços de trabalho. Também dento da universidade, como intolerância e falta de informação das pessoas para lidar com realidades diferentes e convivência pacífica.Por meio desta troca de conhecimento, se pode analisar o papel do professor como facilitador de discussões que respeitem as diferenças, e que proponham soluções para a escola de ensino básico, que será o local de trabalho do futuro professor.

Embora a relação entre teoria e prática seja algo indispensável à formação docente, lamentavelmente, podemos observar que o ensino desenvolvido nas licenciaturas dentro das universidades estabelece pouca, ou nenhuma, relação entre os aspectos teóricos trabalhados nesses espaços e as realidades escolares. Especialmente,com os conhecimentos advindos das práticas pedagógicas dos professores que lá estão e com as realidades dos educandos. Para Pacheco et al.:

A prática que é desenvolvida de modo a relacionar os saberes epistemológicos apreendidos e as experiências vivenciadas no processo de formação docente, por vezes se distancia do real objetivo da ação pedagógica que é a relação teoria e prática.[...] a dicotomia ou a unificação de ambas podem influenciar na constituição da formação do educador (PACHECO et al., 2017, p 332).

O distanciamento entre teoria e prática pode exercer influência negativa na formação do professor e, por consequência, na maneira como ele ensina, pois muitos dos questionamentos e problemas vivenciados pelos professores e estudantes nas escolas e salas de aula, incluindo aí fatores relacionados à diversidade cultural, são objeto de interesse dos pesquisadores e dos próprios professores. Assim, não são se deve separar os conhecimentos práticos, advindos das experiências dos professores (saberes da docência)dos conhecimentos teóricos, advindos de análises críticas que perpassam metodologias específicas, porque os segundos são sobre os primeiros e têm por finalidade, ou deveriam ter, o retorno à prática. Para Pacheco et al.: 


\section{autêntica}

DOI https://doi.org/10.31639/rbpfp.v\%vi\%i.284

[...] a teoria é a forma como o conhecimento se apresenta articulando-se sistematicamente em graus e especificidades, disposto a explicar ou ilustrar ações práticas; enquanto a prática é a constituição da teoria, formulada em ações concretas, podendo ser modificada e modificar as teorias (PACHECO et al., 2017, p. 334).

De acordo com Selles e Ferreira (2009), no lugar de separar teoria e prática é preciso problematizar os traços que distinguem e aproximam os conhecimentos escolares dos conhecimentos científicos e acadêmicos de referência. É preciso [...] focalizar as tensões e os mecanismos próprios da escola, reconhecendo-a como um lugar de produção de conhecimentos e aos professores como elaboradores desses (SELLES; FERREIRA, 2009 , p. 58).É preciso dar voz aos sujeitos, professores e estudantes das escolas, para que levem as suas experiências para as salas de aula das licenciaturas, numa constante relação entre teoria e prática. De igual forma, aproximações entre os licenciandos e os espaços físicos das escolas, das realidades culturais dos sujeitos que nelas transitam como forma de conhecer e compreender as suas reais necessidades e interesses por aprender ciências. Porque o aprender da docência é algo que requer a observação e a reflexão que direcione à reelaboração dos modelos existentes.

Essas vivências, além de serem no espaço escolar, podem acontecer, também, através da exibição de vídeos com depoimentos de professores e estudantes em salas de aula, a exemplo dos vídeos disponibilizados pelos Laboratórios da Faculdade de Educação da USP (http://www.labeduc.fe.usp.br/?videos=o-problema-do-copo, acessado em 27 de junho de 2019), os quais apresentam experiências didáticas sobre vários conteúdos curriculares de ciências, como água, ar, espaço, massa, peso, entre outros. A utilização de vídeos se torna imperativa, especialmente quando existem dificuldades para saídas de campo e visitas aos espaços escolares.

No que tange à saída de campo, ou viagem de campo, destacamos que EDU 354 vem realizando com frequência essa atividade, cujo propósito é sempre gerar oportunidades para que os futuros professores de biologia conheçam as realidades nas escolas e também os saberes culturais dos estudantes, que são pessoas residentes no município de Feira de Santana, ver por exemplo trabalho publicado com outra monitora, relatando uma saída de campo a um centro comercial da cidade, para que lhes fosse possível investigar e compreender os conhecimentos culturais da região relacionados com as plantas e animais e, a partir disto, a elaboração de recursos e sequencias didáticas para o diálogo intercultural, entre os conhecimentos biológicos que são trabalhados nas escolas e os conhecimentos locais sobre as plantas e os animais (BAPTISTA; ARAUJO, 2018).

No semestre em que foi desenvolvido esta pesquisa também foi realizada uma saída de campo com os licenciandos, que foi para o centro comercial da cidade de Feira de Santana. O objetivo foi oferecer oportunidade para que eles observassem esse espaço - particularmente sobre poluição em seus diversos aspectos (atmosférica, hídrica, solo e sonora) - com anotações em diário de campo e, com base nisto, elaborassem recursos didáticos e planos de aula (croqui, paródia, cordel, história em quadrinhos, vídeo e álbum fotográfico) para serem aplicados com estudantes do $6^{\circ}$ ano do ensino fundamental, o que foi inviabilizado, dado ao fato de que as escolas do município estarem de férias. Os licenciandos apresentaram seus respectivos recursos didáticos e planos de aula na sala de aula da UEFS, havendo contribuições mútuas entre eles, a monitora e a professora orientadora. Como é possível notar no relato da monitora que segue, essa experiência prática vivenciada pelos licenciandos contribuiu para que eles, assim como ela mesma, aprendessem na própria ação a importância do planejamento do ensino:

A professora orientadora propôs aos alunos a construção de recursos e planos de aula a partir do que eles observaram no centro da cidade com relação à poluição do ambiente. Acredito que isso 


\title{
autêntica
}

DOI https://doi.org/10.31639/rbpfp.v\%vi\%i.284

\begin{abstract}
foi bom porque Feira de Santana é uma cidade muito poluída no comércio, muita gente, muitos cartazes, muitas lojas com sons de altura elevada, esgoto e lixos espalhados no solo por todos os lados. Achei interessante e importante porque ela propôs que o melhor recurso didático seria analisado comigo para construção de um artigo,onde eles também seriam os autores. Nitidamente vejo que eles se sentiram mais motivados a participação da proposta a ser elaborada[...]. A professora destacou sobre a importância de ser ter um bom planejamento para que o recurso didático contribua da melhor forma possível para o aprendizado dos alunos nas escolas. Eu realmente acho que é muito bom, porque um bom professor é aquele que contribui não só com os conteúdos, mas também valoriza e potencializa as oportunidades para que os alunos alcancem os objetivos, vencendo desafios e obstáculos. Uma das maiores dificuldades que percebo é que eles não sabem fazer um plano de aula, o que foi melhorado quando a professora orientadora explicou a eles com detalhes para que assim eles pudessem conseguir [.....A professora parabenizou aos grupos, e principalmente deu destaque a um dos grupos que fez uma história em quadrinhos, cujo tema foi poluição do ar. Escolhemos esse grupo para a elaboração do artigo posteriormente.
\end{abstract}

O trecho acima nos impulsiona a afirmar que tratar aspectos teóricos ligados à prática é algo indispensável à formação do professor, todavia isso não pode ser concretizado se não estiver acompanhado de planejamento. Essa premissa é válida não apenas para a formação continuada, como comumente se entende, mas, também, para a formação inicial, quando os futuros professores universitários poderão, no corpo de cada componente curricular, elaborar planos e/ou sequências didáticas. Observa-se que esses professores, embora conscientes da necessidade de consideração e respeito pela diversidade cultural nos momentos de ensino e aprendizagem,demonstram dificuldades em desenvolver habilidades neste sentido.

\section{Categoria 4:A empatia para o despertar do interesse por ser professor e construção da identidade docente em ciências}

A monitora reconheceu que o processo de construção da identidade docente não depende apenas de fatores externos, como dos cursos de formação, dos docentes nas universidades, dos currículos, dos recursos didáticos etc., mas também de fatores internos à própria pessoa, como, por exemplo, da tomada de consciência do seu papel como educador (IZA et al, 2014). Podemos analisar esta afirmativa na seguinte transcrição:

O se identificar como o que vai trabalhar, e o para que está se formando é algo que considero como totalmente relacionado com os ambientes nos quais os futuros professores estão, como o modo como se percebe os acontecimentos ao redor. A monitoria funciona como um espaço de questionamentos sobre a docência. O que estou observando, as discussões de futuro e presente estão me ajudando na análise do que tenho sido e do que quero ser como profissional. Vejo que a monitoria pode ser um processo de encontro e empatia com o ser professor e para que estou me formando. Como posso favorecer para que este processo seja ainda melhor para mim enquanto futuro docente já formada? Como sou como licencianda na UEFS? Será que estou me empenhando para aproveitar ao máximo como estou aqui na monitoria?

De maneira associada a esse reconhecimento, a monitora destaca a importância do "encontro e empatia com o ser professor" para a sua formação profissional. A empatia como um processo psicológico complexo, de sentir-se no lugar do outro, que embora estivesse na condição de monitorar a professora orientadora, conseguiu colocar-se como professora e, ao mesmo tempo, licencianda em biologia, assim como seus colegas:

Estou conseguindo permanecer com uma boa relação com os alunos, que também são licenciandos como eu, pois vejo que a monitora serve como intermediador dos estudantes para com 


\title{
autêntica
}

DOI https://doi.org/10.31639/rbpfp.v\%vi\%i.284

\begin{abstract}
a docente, como ser professora também, o que contribui para o desenvolvimento da disciplina e de todos. Os conteúdos da disciplina contribuem para a reflexão de como a diversidade cultural é um assunto que permeia em todos os espaços da formação de um bom profissional, pois assim este aprende a construir uma boa relação com indivíduos que constitui o espaço escolar, desde aqui na universidade.
\end{abstract}

Por empatia entendemos a capacidade de um sujeito sentir as emoções das outras pessoas e, de igual forma, imaginar o que essas pessoas estão sentindo. Neste sentido, ter empatia com o ser professor significa colocar-se no lugar do professor que já atua nas salas de aula, a partir de observações, de interações e reflexões. Aempatia contribui para a formação da identidade docente, porque permite colocar-se no lugar do outro, constituindo-se num corpo organizado de saberes e num conjunto de valores que vão sendo formados e interiorizados, criando ou gerando uma identidade que é social e envolve procedimentos institucionalizados de formação específica (BENITES, 2012). Envolve o emocional por meio da afetividade e o cognitivo através da capacidade de analisar e decidir sobre os estados mentais de outras pessoas, sobre o que elas estão pensando (CUFF et al., 2016). Neste sentido, destacamos a relação de afetividade entre a monitora e professora, despertada pelo respeito e confiança entre ambas no expressar dos pensamentos e compartilhamento de ações.

\section{Categoria 5: A contribuição das rodas de conversa relacionadas às questões de raça, sexualidade, gênero e inclusão}

Para Paiva et al (2016), o ensino de ciências não pode deixar de abordar temas relativos a alterização científica, porque dentro do processo histórico da ciência, é fato, ocorreram e ainda ocorrem marginalização de grupos sociais e culturais, destacando aí o racismo e o sexismo. Temas como esse merecem discussão e reflexão nas salas de aula, pois isto poderá contribuir para o rompimento da subjugação de diversos grupos sociais, deixando explicito como isso vem acontecendo historicamente, inclusive na atualidade.

As anotações da monitora,sobre a sua participação nas as aulas de EDU 354, revelam que os licenciandos em Biologia da UEFS estão atentos à marginalização que está presente na realidade escolar e importância de mudanças nessa situação:

Vejo que nas rodas de conversas ocorre discussão entre os alunos, sobre temas que são de grande relevância para o ensino de ciências, para que a visão da escola não perpetue pressupostos de estereotipagem, principalmente com relação ao gênero, sexualidade, raça, etnia das pessoas. Também com relação as pessoas com necessidades especiais e inclusão delas nas escolas. Eles falam como é importante que eles, como futuros professores, possam ajudar a construir e persistir em discussão de respeito e convivência com as diferenças, pois é preciso estar ciente de sua responsabilidade e importância de sua atuação profissional. [...] Por meio desta disciplina eu abri os meus olhos como ser profissional de educação, em reflexões om perguntas: - Qual o papel do professor, não só como profissional, mas também como cidadão dentro da escola? - Como a minha atuação durante o estágio da licenciatura, e até mesmo nesta disciplina como monitora, pode contribuir para que os alunos nas escolas não propagem a violência e o desrespeito? Acredito que essas questões vão me ajudar, porque ser professor é reconhecer os erros e sempre estar disposto a mudança de posição e atitude. Por isso vejo a necessidade de propormos mais discussões sobre estes assuntos dentro de todas as disciplinas, pois dentro de uma grade curricular tão extensa, esta discussão é deixada de lado. 


\section{autêntica}

DOI https://doi.org/10.31639/rbpfp.v\%vi\%i.284

A preocupação da monitora expressa na transcrição acima, envolvendo a sua própria formação e a dos seus colegas, é condizente com nossos achados na literatura. De acordo com Cordeiro e Buendgens (2012), a escola é um espaço importante para que ocorra a formação intelectual e ética do sujeito e eliminação dadiscriminação. Entendemos que é preciso incluir abordagens sobre discriminação e intolerância nas aulas dos componentes curriculares das licenciaturas, pois isto ajudará nas reflexões que promovem mudanças de práticas que estejam equivocadas neste sentido, como, por exemplo, a realização de atividades relacionadas apenas em datas comemorativas: dia do índio. 


\section{autêntica}

DOI https://doi.org/10.31639/rbpfp.v\%vi\%i.284

\section{CONSIDERAÇÕES FINAIS}

A partir dos resultados apresentados neste trabalho discutimos as vivências de uma licencianda em biologia da UEFS como monitora do componente curricular Pluralidade Cultural e Inclusão escolar (Código EDU 354 no Departamento de Educação UEFS).

De maneira geral, essas discussões indicam que a monitoria vivenciada pela licencianda contribuiu para que ela desenvolvesse empatia pela docência em ciências que seja sensível à diversidade cultural, particularmente afetividade por ser professora de ciências e biologia, que buscará respeitar e considerar os diferentes conhecimentos e práticas culturais que estão presentes no universo escolar. Esta conclusão decorre do seu acompanhamento e observações sobre as atividades durante as aulas, o que the permitiu reflexões acerca da docência e formação de professores, colocando-se no lugar da professora que ela estava acompanhando e como futura professora de biologia.

Entendemos o quão importante é a reflexão da licencianda como monitora, coparticipante e colaboradora durante as aulas para que os licenciandos possam identificar-se, ou não, como futuro profissional da educação. Importa destacar que não estamos concebendo a aprendizagem da docência como encerrando-se na graduação, e nesse contexto na monitoria. A formação docente, como bem indica Nóvoa(1992), a aprendizagem da docência é um contínuo, para além da formação universitária, e envolve a própria pessoa, como agente e a escola, como lugar de crescimento profissional constante.

A monitoria constitui uma entre as inúmeras possibilidades de formação do professor, para o desenvolvimento afetividade pela docência, no sentido de projetar-se como professora de ciências sensível à diversidade cultural, além de outros aspectos. Ser monitor, nesse sentido, é empenhar-se ao máximo para auxiliar o professor/ orientadora compreender as realidades, necessidades e anseios dos demais licenciandos, auxiliando-os nas suas aprendizagens.

A partir do acima exposto, sinalizamos como necessário e importante a continuidade de oferta e disponibilização de projetos de monitoria para os licenciandos, não apenas de Biologia da UEFS, mas também de outras áreas e de outras universidades que queiram gerar oportunidades para que os futuros professores aprofundem seus embasamentos teóricos de maneira associada à prática pedagógica.

A monitoria, para Amorim et al. (2012, p. 33) "... constitui espaço de pesquisa, de reflexão, de aprendizagem e profissionalização da docência". Assim, consideramos que os licenciandos necessitam ser apoiados como professores iniciantes e a monitoria facilita o trabalho colaborativo entre licenciandos e professores, podendo reflexões e enriquecimento mútuo de saberes e práticas. De igual forma, melhorias na qualidade de ensino do componente curricular que está sendo monitorado. 


\section{autêntica}

DOI https://doi.org/10.31639/rbpfp.v\%vi\%i.284

\section{REFERÊNCIAS}

AMORIM, R. M. de; LIRA, T. H. de; OLIVEIRA, M. P. de; PALMEIRA, A. P. O papel da monitoria para a formação de professores: cenários, itinerários e possibilidades no contexto atual. Revista Exitus, v. 2, n. 2, p. 33-47, 2012.

BAPTISTA, G. C. S. Do cientificismo ao diálogo intercultural na formação do professor e ensino de ciências. Interações, v. 10, n. 31, p. 28-53, 2014.

BAPTISTA, G. C. S.;ARAUJO, G. Desenvolvimento para a competência intercultural na formação do professor de biologia pelas práticas da etnobiologia. Gaia Scientia, v. 12, n. 2, p. 76-88, 2018.

BARDIN, L. Análise de conteúdo. Lisboa: Edições 70, 2006.

BENITES, L. C. O professor-colaborador no estágio curricular supervisionado em Educação Física: perfil, papel e potencialidades. 180f. Tese (Doutorado em Ciência da Motricidade). Instituto de Biociências, Universidade Estadual Paulista, Rio Claro, 2012.

BORTONI-RICARDO, S. T. O professor pesquisador: introdução à pesquisa qualitativa. São Paulo: Parábola Editorial, 2008.

CARVALHO, M. Universidade e Escola Básica: Formação inicial e continuada de professores que ensinam matemática em espaços colaborativos. Formação Docente, v. 9, n. 17, p. 65-76, 2017.

CORDEIRO, A. F. M.; BUENDGENS, J. F. Preconceitos na escola: sentidos e significados atribuídos pelos adolescentes no ensino médio. Revista Semestral da Associação Brasileira de Psicologia Escolar e Educacional, v. 16, n. 1, p. 45-54, 2012.

CUFF, B. M. P.; BROWN, S. J.; TAYLOR, L; HOWAT, D. Empathy: A Review of the Concept, Emotion Review, v. 8, n. 2, p. $144-153,2016$

DANTAS, C. R. da S.; MASSONI, N. T.; SANTOS, F. M. T. dos. A avaliação no Ensino de Ciências Naturais nos documentos oficiais e na literatura acadêmica: uma temática com muitas questões em aberto. Ensaio: Avaliação e Políticas Públicas em Educação, v. 25, n. 95, p. 440-482, 2017.

FRISON, L. M. B. Monitoria: uma modalidade de ensino que potencializa a aprendizagem colaborativa e autorregulada. Pro-Posições, v. 27, n.1, p.133-153, 2016.

FRISON, L. M. B; MORAES, M. A. C. de. AA práticas de monitoria como possibilitadoras dos processos de autorregulação das aprendizagens discentes.Poíesis Pedagógica, v. 8, n. 2, p.144-158, 2010.

IZA, V.F.D.; BENITES, C.L.; NETO,S.L.; CYRINO,M.; ANANIAS, V.E; ARNOSTI,P.R.; NETO,S.S. Identidade docente: As várias faces da constituição do ser professor. Revista Eletrônica de Educação, v. 8, n. 2, p. 273292, 2014.

LEITE, P.A.E; RIBEIRO,S.E; LEITE,G.K; ULIANA,R.M. Formação de profissionais da Educação alguns desafios e demandas na formação inicial de professores na contemporaneidade. Educação \& Sociedade, v. 39, n. 144, p.721-737, 2018. 


\section{autêntica}

DOI https://doi.org/10.31639/rbpfp.v\%vi\%i.284

NÓVOA, A. Os Professores e sua Formação,Lisboa: Publicações Don Quixote, Ltda., 1992.

PAIVA, A. de S.; SOUZA, H. C.; SEPULVEDA, C.; ARTEAGA, J. S. Baartman, Lacks e o corpo da mulher negra como paradigma de alteridade na história da biologia. In: 15 Seminário Nacional de História da Ciência e da Tecnologia, 2016, Florianópolis. Caderno completo 15 Seminário Nacional de História da Ciência e da Tecnologia, p. 1-17, 2016.

PACHECO, W. R. de S.; BARBOSA, J. P. da S.; FERNANDES, D. G. A relação teoria e prática no processo de formação docente. Revista de Pesquisa Interdisciplinar, n. 2, suplementar, p. 332- 340, 2017.

PIMENTA, S. G.; LIMA, M. S. L. Estágio e docência: diferentes concepções. Revista Poíesis, v. 3, n. 3 e 4, p.5-24, 2006.

RÁTIVA VALENDIA, M. Método Lancaster no Brasil e na Colômbia. Formação Docente, v. 5, n. , p. 96-103, 2013

SELLES, S. E.; FERREIRA, M. S. Saberes docentes e disciplinas escolares na formação de professores em Ciências e Biologia. SELLES, S. E. et al. (Orgs.). Ensino de Biologia: histórias, saberes e práticas formativas. p. 49-69. Uberlândia: EdUFU, 2009.

SOUZA, E. C. A arte de contar e trocar experiências: reflexões teórico-metodológicas sobre história de vida em formação. Revista Educação em Questão. v. 25, n. 11, p. 22-39, 2006.

VALENCIA, C. H. Las Escuelas Normales y la formación del magisterio. Primera mitad del século XX. Colección tesis doctorales RUDECOLOMBIA, Universidad de Caldas, 2006.

VEIGA, I. P. A. Organização Didática da Aula: Um projeto colaborativo de ação imediata. In: Veiga, I. P. A. (Org.). Aula: Gênese, Dimensões, Princípios e Práticas. 1ª ed. v. 1, p. 267-298, Campinas: Papiros, 2008.

VERAS, R. da S.; FERREIRA, S. P. A. A afetividade na relação professor-aluno e suas implicações na aprendizagem, em contexto universitário. Educar em Revista, n. 38, p. 219-235, 2010.

BAPTISTA, G. C. S.; SANTOS, L. C.;

Monitoria como espaço de formaçãodocente inicial em biologia sensível à diversidade cultural

Formação Docente - Revista Brasileira de Pesquisa sobre Formação de Professores

Vol. 11, no. 22 (p. 95-110) 31 dez. 2019 
